\title{
"SOLO SÍ ES SÍ", PERO DE VERDAD. UNA RÉPLICA A GIMBERNAT
}

\author{
Eduardo Ramon Ribas* \\ Patricia Faraldo Cabana**
}

El caso de la Manada ha puesto en marcha una reforma de los delitos sexuales en España que no acaba de gustar a muchos. En julio de 2018, tras la primera sentencia del caso, el anuncio de Carmen Calvo, vicepresidenta del Gobierno y entonces Ministra de Igualdad, de que se promovería una reforma del Código Penal y de la Ley de Enjuiciamiento Criminal para situar como clave de los delitos sexuales la falta de consentimiento expreso de la víctima dio lugar a una desaforada reacción de un sector de los medios de comunicación y de las redes sociales. Su observación de que "si una mujer no dice sí expresamente,

Recibido:marzo 2020. Aceptado: mayo 2020

* Catedrático de Derecho Penal.

Facultad de Derecho de la Universitat de les Illes Balears. Edificio Gaspar Melchor de Jovellanos, Campus Universitario, Ctra. de Valldemossa Km 7.5, 07122 Palma de Mallorca. Email: eduardo.ramon@uib.es

** Catedrática de Derecho Penal. ORCID ID: 0000-0001-7420-3749

Facultad de Derecho, Universidade da Coruña, Campus de Elviña, 15071, A Coruña. Email: patricia.faraldo@udc.es 
todo lo demás es no", que, por tanto, "solo sí es sí", la convirtió en el epítome de la ridiculez del feminismo, con hombres y mujeres burlándose de la idea de que sería necesario un "contrato sexual" o una App para hacer constar el consentimiento antes de mantener cualquier tipo de relación sexual. Al mismo tiempo, con solo esa frase, y ese es sin duda un primer efecto positivo, la vicepresidenta del Gobierno abrió un debate de gran calado sobre la violencia sexual en España, que se ha recrudecido con la aprobación por el Consejo de Ministros del anteproyecto de ley orgánica de la garantía de la libertad sexual el 3 de marzo de 2020.

El anteproyecto modifica la regulación de los delitos sexuales contra personas adultas en dos aspectos fundamentales (entre muchos otros que no pueden ser objeto de valoración aquí). Por un lado, se considera que existe agresión sexual cuando se realiza cualquier acto que atente contra la libertad sexual de otra persona sin su consentimiento, puntualizándose que "se entenderá que no existe consentimiento cuando la víctima no haya manifestado libremente por actos exteriores, concluyentes e inequívocos conforme a las circunstancias concurrentes, su voluntad expresa de participar en el acto". Por otro lado, desaparece la distinción actual entre abusos y agresiones sexuales sobre la base de la utilización de violencia o intimidación, unificándose ambas figuras. El tipo básico del nuevo delito de agresión sexual considera "en todo caso agresión sexual los actos de contenido sexual que se realicen empleando violencia, intimidación o abuso de una situación de superioridad o vulnerabilidad de la víctima, así como los que se ejecuten sobre personas que se hallen privadas de sentido o de cuya situación mental se abusare y los que se realicen cuando la víctima tenga anulada por cualquier causa su voluntad". Así se da respuesta, pues, a dos de los eslóganes coreados en las manifestaciones por el caso de la Manada: "solo sí es sí" y "no es abuso, es violación". Cabe preguntarse, no obstante, si estos cambios son necesarios. Al fin y al cabo, el Tribunal Supremo, aplicando la redacción vigente, ha podido dar una solución en esa línea al caso de la Manada. 
La respuesta es que sí: son cambios necesarios. En contra, ha señalado Gimbernat que la equiparación de la violencia o intimidación con otras situaciones que también suponen la ausencia de consentimiento, como el abuso de situación de superioridad, "es injusta, porque - a pesar de la diferencia material que existe entre ellos- trata de igual manera supuestos de hecho desiguales"1. Y alega, en apoyo de la distinción actual entre abuso y agresión sexual, que nadie ha pedido que desaparezcan la violencia o intimidación como factor de agravación "en los restantes delitos del CP actual", citando a estos efectos los delitos contra la propiedad (robo, estafa y apropiación indebida) y contra los derechos de los trabajadores, el allanamiento de morada y la usurpación, sin que se alcance a comprender, a su juicio, "qué diferencia determinante concurre en los delitos contra la libertad sexual" para que allí sí se justifique la eliminación. Entiende que, "si se quiere suprimir la diferencia entre acceso carnal con violencia o intimidación, o sin ellas, entonces este criterio valorativo de equiparación habría que aplicarlo también, consecuentemente, a los restantes delitos del CP que se

1 "Ya que no es equiparable que el autor consiga tener acceso carnal con una mujer en un descampado, después de agredirle fisicamente, o bajo la amenaza de que, si se niega, la estrangulará -un caso inequívoco de agresión sexual (violación) violenta, en el primer caso según el CP vigente, y de violación intimidatoria, en el segundo-, que el comportamiento que lleva a cabo el idolatrado y admirado profesor de 49 años, quien, prevaleciéndose de la autoridad que ejerce sobre su abducida alumna de 18, la accede carnalmente (supuesto indiscutible de abuso sexual, según el todavía vigente art. 181.3 CP)", según sostiene.

En relación con este segundo ejemplo, es preciso destacar un error: el idolatrado y admirado profesor de 49 años que se prevale de la autoridad que ejerce sobre su abducida alumna de 18 años para mantener relaciones sexuales con ella realiza una conducta atípica. En efecto, es preciso diferenciar los supuestos de obtención del consentimiento con prevalimiento de una situación de superioridad manifiesta que coarta la libertad de la una persona y se convierte, por ello, aunque tenga 18 o más años, en víctima (art. 181.3 $\mathrm{CP})$ de los casos en que una persona, interviniendo engaño o abusando de una posición reconocida de autoridad, confianza, o influencia sobre otra persona, mayor de dieciséis años y menor de dieciocho, realiza con ella actos de carácter sexual, tipificados en el art. 182 CP. 
han servido precisamente de esos dos elementos de la violencia $y$ de la intimidación para establecer penas más o menos graves según que concurran o no en la ejecución del delito... según este criterio valorativo que aplica el Anteproyecto a los delitos contra la libertad sexual, habría que expurgar el CP vigente, para encontrar todos los delitos en los que, frente al elemento común del tipo básico, concurre además la violencia o intimidación, a fin de suprimir ese supuestamente estúpido criterio como factor de agravación".

El argumento es cautivador, pero falaz.

$1^{\circ}$.- En primer lugar, porque no tiene en cuenta la diferente estructura y bien jurídico de los delitos que menciona, y, en particular, que la libertad sexual de la víctima, entendida como su derecho a no verse involucrada, activa o pasivamente, en conductas de contenido sexual a las que no ha accedido, se ve tan afectada cuando la penetran a punta de navaja como cuando lo hacen aprovechando que estaba borracha o drogada ${ }^{2}$. Sin embargo, cuando en vez de quedarse con la bicicleta prestada, el

2 A juicio de Gimbernat, por el contrario, la diferencia de penalidad ("que, por lo demás, los delitos contra la libertad sexual comparten con muchos otros") entre el hecho cometido sin violencia ni intimidación, por una parte, y el cometido con ellas, por otra, es completamente plausible: "en primer lugar, porque en este último caso, además de la lesión del bien jurídico protegido en concreto, se produce una vulneración de otro interés jurídico, a saber: la lesión efectiva de la integridad fisica de la víctima (lo cual, por cierto, no es verdad: aunque insistiremos en ello, no siempre se produce dicha lesión, y si tiene lugar, deberá ser castigada a través del concurso real o medial, estimando cometidos dos delitos), o la amenaza dirigida contra ella de causarle un mal grave (como veremos, esta amenaza merece la consideración legal de coacción y su lesión no incrementa la que sufre la libertad sexual de la víctima); $y$, en segundo lugar, porque, cuando se acude a la violencia o a la intimidación, el autor está poniendo de manifiesto una brutalidad que no concurre en la comisión de los tipos penales básicos en los que esa violencia o esa intimidación están ausentes". Esta brutalidad no lesiona más la libertad sexual y si es constitutiva de ensañamiento o de actos particularmente degradantes o vejatorios podrá apreciarse la correspondiente circunstancia agravante. 
ladrón vence la resistencia del propietario dándole unos golpes en la cabeza o amenazándole con hacerlo (por usar el ejemplo de Gimbernat), al atentado contra el patrimonio del titular (el único contemplado por el delito de hurto) se suma otro, contra su libertad (dejamos a un lado la salud o integridad física en el caso de los golpes, que merecería, si se vieran afectadas, un concurso de delitos), que justifica de por sí una mayor pena. Impedir a alguien con violencia (término que comprende, según reiterada jurisprudencia, tanto la física como la intimidatoria y la violencia sobre las cosas e, incluso, supuestos en los que fácilmente se advierte su ausencia, pero cuyo efecto es igualmente impedir realizar lo que se desea hacer y la ley no prohíbe) hacer lo que no quiere y, sobre todo, compelerle a efectuar lo que no quiere (en este caso, con independencia de que sea justo o injusto ${ }^{3}$ ) es, al fin y al cabo, siempre un delito de coacciones. Preciso es subrayarlo: el delito de robo con violencia o intimidación es una coacción específicamente castigada ${ }^{4}$, que encerrará comúnmente, por otra parte, una detención ilegal que, en la medida en que resulte inherente al robo y no exceda del tiempo estrictamente necesario para su comisión, se entiende castigada con la pena propia del robo. La pena prevista por dicho delito de robo traduce, pues, un doble contenido de injusto: un desvalor patrimonial y un atentado contra la libertad personal, concretamente contra la libertad de obrar. El delito de agresión sexual, por el contrario, asimismo es obligado enfatizarlo, solo atenta contra un bien jurídico, resultando indiferente que se cometa, o no, utilizando violencia o intimidación: la libertad de obrar, particularmente, la libertad de

3 Esta segunda modalidad de coacción es, conforme el Código Penal, más grave: no se exige, al menos de forma expresa, violencia (compeler significa, según el Diccionario de la RAE, obligar a alguien, con fuerza o por autoridad, a que haga lo que no quiere) y, además, como hemos dicho, es indiferente que lo compelido a hacer sea justo o injusto.

4 La intimidación a la que alude el delito de robo tipificado en el art. $242 \mathrm{CP}$ debe consistir en el anuncio de un mal inmediato y la condición, la entrega de la cosa mueble, debe exigirse igualmente con inmediatez: se lesiona, por tanto, la libertad de obrar, la misma que resulta protegida por el delito de coacciones. 
obrar en el ámbito sexual, de participar en un comportamiento de esta naturaleza. En efecto, el hecho de que se emplee violencia o intimidación no afecta en mayor medida al bien protegido: entre el delito de coacciones y el de agresión sexual existe una evidente relación de progresión delictiva. Y si la utilización de aquellas llevara consigo la causación de lesiones, estas, como hemos adelantado, deberán ser castigadas separadamente ${ }^{5}$.

En los delitos contra los derechos de los trabajadores, de allanamiento de morada y de usurpación se reproduce, utilizadas la violencia o la intimidación, una situación análoga, si no equivalente. En ninguno de dichos delitos es la libertad el objeto de protección, por lo que recurrir al empleo de aquellos medios incorpora una nueva dimensión de injusto: se comete una coacción (por cierto, específicamente sancionada, lo que impedirá la aplicación del artículo $172 \mathrm{CP}$ ) y, por consiguiente, un atentado contra la libertad, que el legislador ha considerado debe ser castigada no de forma general, sino especial, sumándola, en el seno de las normas que prevén su castigo, al atentado contra los derechos de los trabajadores, contra la inviolabilidad del domicilio o contra el derecho de posesión.

$2^{\circ}$.- En segundo lugar, porque no es verdad, como da a entender Gimbernat, que en el Código Penal siempre se tenga en cuenta la violencia o intimidación como factor de agravación cuando concurre. En particular, no se tiene en cuenta en los delitos contra la vida (salvo que la violencia llegue hasta el punto del ensañamiento, da igual que matemos a alguien a cuchilladas o que lo hagamos con somníferos), contra la libertad ambulatoria (da igual que detengamos a alguien, privándolo de su libertad, drogándolo, reduciéndolo a golpes o cerrando con llaves la puerta de la habitación o estancia en la que se halla),

5 Respondemos, así, a la observación siguiente de Gimbernat, según el cual, "no se alcanza a comprender qué diferencia determinante concurre en los delitos contra la libertad sexual, frente a otros del CP en los que, como acabo de indicar, la mayor o menor gravedad de la pena se hace depender también, y precisamente, de si concurre, o no, la violencia o la intimidación". 
contra la salud (tendrá que reconocer Gimbernat que la pena es la misma si transmitimos dolosamente el VIH a nuestra víctima mediante una placentera relación sexual o utilizando violencia física, inyectando, por ejemplo, la sustancia mientras sujetamos a la víctima, o intimidándola con una pistola; también merecen idéntico trato penal la causación de la impotencia suministrando determinada sustancia o amputando con una sierra radial el órgano genital masculino), la integridad moral ${ }^{6} \mathrm{o}$ descubrimiento y revelación de secretos.

En otros delitos sí se hace mención expresa del uso de violencia o intimidación, pero se equipara su utilización a la del engaño, el abuso de una situación de superioridad, de necesidad o de vulnerabilidad de la víctima o, en fin, de otros medios o artificios.

Es el caso de los arts. 284 (serán castigados, dice, quienes, empleando violencia, amenaza, engaño o cualquier otro artificio, alterasen los precios que hubieren de resultar de la libre concurrencia de productos, mercancías, instrumentos financieros, contratos de contado sobre materias primas relacionadas con ellos, índices de referencia, servicios o cualesquiera otras cosas muebles o inmuebles que sean objeto de contratación), 362 quinquies (que agrava los comportamientos en él descritos cuando se "haya empleado engaño o intimidación"), 470 (que prevé el castigo del particular que proporcionare la evasión a un condenado, preso o detenido, bien del lugar en que esté recluido, bien durante su conducción, en el que la conducta se agrava si se

$6 \quad$ El art. 173.1 CP prevé el castigo de quien "infligiera a otra persona un trato degradante, menoscabando gravemente su integridad moral'. No se prevé una agravación si se usa violencia o intimidación. Tampoco en los delitos de acoso laboral o inmobiliario tipificados en el propio art. $173.1 \mathrm{CP}$, ni en los delitos de torturas. Los arts. 174 y 175 CP, cuya autoría está reservada a autoridades o funcionarios públicos, describen así el tipo objetivo: someter a una persona " a condiciones o procedimientos que por su naturaleza, duración u otras circunstancias, le supongan sufrimientos físicos o mentales, la supresión o disminución de sus facultades de conocimiento, discernimiento o decisión", o que (y es importante remarcarlo), "de cualquier otro modo, atenten contra su integridad moral". 
emplea "al efecto violencia o intimidación en las personas, fuerza en las cosas o soborno"), 616 ter (será castigado "el que con violencia, intimidación o engaño, se apodere, dañe o destruya una aeronave, buque u otro tipo de embarcación o plataforma en el mar, o bien atente contra las personas, cargamento o bienes que se hallaren a bordo de las mismas") o de los siguientes:

- el art. $144 \mathrm{CP}$, que, tras ordenar el castigo de quien produzca el aborto de una mujer, sin su consentimiento, establece que "las mismas penas" se impondrán "al que practique el aborto habiendo obtenido la anuencia de la mujer mediante violencia, amenaza o engaño".

- el art. 172 bis CP, el cual, prevista la punición de quien, con intimidación grave o violencia compeliere a otra persona a contraer matrimonio, preceptúa que se impondrá la misma pena "a quien, con la finalidad de cometer los hechos a que se refiere el apartado anterior, utilice violencia, intimidación grave o engaño para forzar a otro a abandonar el territorio español o a no regresar al mismo".

- el art. 177 bis $1 \mathrm{CP}$, que manda castigar, como reo de trata de seres humanos, a quien, sea en territorio español, sea desde España, en tránsito o con destino a ella, "empleando violencia, intimidación o engaño, o abusando de una situación de superioridad o de necesidad o de vulnerabilidad de la víctima nacional o extranjera, o mediante la entrega o recepción de pagos o beneficios para lograr el consentimiento de la persona que poseyera el control sobre la víctima", la captare, transportare, trasladare, acogiere, o recibiere, incluido el intercambio o transferencia de control sobre esas personas, con cualquiera de las finalidades que acto seguido enumera el precepto.

- el art. 183 ter CP, según el cual, será castigado el que, a través de internet, del teléfono o de cualquier 
otra tecnología de la información y la comunicación contacte con un menor de dieciséis años y proponga concertar un encuentro con el mismo a fin de cometer cualquiera de los delitos descritos en los arts. 183 y $189 \mathrm{CP}$, siempre que tal propuesta se acompañe de actos materiales encaminados al acercamiento. "Las penas", dice, "se impondrán en su mitad superior cuando el acercamiento se obtenga mediante coacción, intimidación o engaño".

- el art. $187 \mathrm{CP}$, que impone la misma pena a quien, "empleando violencia, intimidación o engaño, o abusando de una situación de superioridad o de necesidad o vulnerabilidad de la víctima", determine a una persona mayor de edad a ejercer o a mantenerse en la prostitución.

Incluso en los delitos contra el patrimonio, en cuyo seno se diferencia entre hurto, robo con fuerza en las cosas y robo con violencia o intimidación, la importancia del empleo de violencia o intimidación para consumar una lesión del patrimonio ajeno debe relativizarse. El robo con violencia o intimidación es más grave, sin duda, que el hurto, pero la diferencia con el robo con fuerza en las cosas es menos evidente. La pena asociada a este es, en principio, prisión de uno a tres años, pero, concurriendo las circunstancias previstas en el art. $235 \mathrm{CP}^{7}$, la pena que se impondrá será, dice el art. $240 \mathrm{CP}$, prisión de dos a cinco años. Esta es, precisamente, la pena propia del robo con violencia o intimidación, que se impondrá en su mitad superior si se hace uso de armas u otros medios igualmente peligrosos, pudiéndose imponer una pena de prisión de uno a dos años "en atención a la menor entidad de la violencia o intimidación ejercidas". En este caso, se castigaría más un robo con fuerza en las cosas que un robo con violencia o intimidación (de menor entidad).

7 Entre ellas, por ejemplo, la multireincidencia, poner a la víctima o a su familia en grave situación económica o tener las cosas sustraídas valor artístico, cultural, histórico o científico. 
La pena propia de los delitos de estafa, administración desleal o apropiación indebida ${ }^{8}$ es, según anuncian sus tipos básicos, prisión de seis meses a tres años, pero, si se dan las circunstancias previstas en el art. $250 \mathrm{CP}$, sube a prisión de uno a seis años y multa de seis a doce meses; o, incluso, prisión de cuatro a ocho años y multa de 12 a 24 meses. El delito de robo con violencia tiene un límite superior en todo caso de cinco años. Estos otros delitos patrimoniales, en los que no es un requisito el empleo de violencia o intimidación, pueden superar, muy manifiestamente, este límite. Es más grave, por tanto, según el Código Penal, cometer una estafa sobre una cosa de primera necesidad aprovechándose de la credibilidad empresarial o profesional (cuatro a ocho años de cárcel) que robar con violencia o intimidación dicha cosa de primera necesidad (dos a cinco años de prisión, a menos que la violencia o intimidación ejercidas lo sean de menor entidad, en cuyo caso se impondrá la pena de prisión de uno a dos años).

En el Código Penal conviven, por tanto, figuras delictivas que sí otorgan relevancia (o mucha relevancia) al hecho de que se utilice violencia o intimidación, con otras que ignoran totalmente la presencia de estas o que la equiparan con otros medios no violentos (engaño, soborno, abuso de situación de necesidad, vulnerabilidad o superioridad). Incluso el delito de coacciones, tradicionalmente identificado con el empleo de violencia (para impedir hacer u obligar a realizar un determinado comportamiento), ha sido interpretado de forma tan extensiva (muchas veces superando los límites impuestos por una interpretación que jamás debería superar el tenor literal de la ley) que incluye hoy supuestos de violencia o fuerza en las cosas junto con otros en los que propiamente no la hay.

Nadie, al menos que sepamos, ha propuesto reformar los delitos de homicidio, lesiones, aborto, detenciones, contra la integridad moral o de descubrimiento y revelación de secretos, a fin de prever su agravación si se emplea violencia o intimidación.

8 Del art. 253 CP. 
¿Habría que expurgar el Código Penal vigente a fin de eliminar todas las agravaciones cuyo fundamento es el uso de violencia o intimidación? ¿O todo lo contrario y prever en todo caso que dicho uso fundamentará la imposición de penas agravadas y siempre en mayor medida que las que deberían resultar del empleo de otros medios no violentos?

Ya hemos visto que la utilización de violencia o intimidación fundamenta, desde la perspectiva del contenido de injusto de muchos delitos, la agravación de la pena, pues se produce una doble afección de bienes jurídicos. En muchas figuras, sin embargo, se ha considerado innecesario introducir previsiones análogas. No es ocioso recordar, al respecto, que la individualización de la pena es una fase capaz de traducir, muchas veces con marcos penales muy generosos, el desvalor de las circunstancias personales del delincuente o de otras circunstancias que, como señala el art. $66.1 .6^{\circ} \mathrm{CP}$, determinan una mayor o menor gravedad del hecho.

Gimbernat vincula, por otra parte, la eliminación de la violencia o intimidación en los delitos sexuales con la dificultad de distinguir entre la intimidación y el abuso de situación de superioridad, un problema que "pertenece a la naturaleza de las cosas". En realidad, la justificación va bastante más allá de esa dificultad de delimitación, que existe ${ }^{9} \mathrm{y}$ ha sido resaltada en repetidas ocasiones tanto en la doctrina como en la jurisprudencia. Lo que muchas veces se presenta como blanco o negro es una escala de grises, no solo porque en los abusos sexuales se incluyen casos de violencia o intimidación considerados "menores" o "de segundo grado", y, por tanto, insuficientes para permitir

9 Y no solo, por cierto, como acertadamente observa Gimbernat, en estos delitos, sino en muchos otros. También, por otra parte, con proyección mucho más generalista, en previsiones de la parte general: en la distinción, por ejemplo, entre actos preparatorios y actos ejecutivos, impunes los primeros con carácter general (cuya pena, sin embargo, a diferencia de lo que señala aquel autor, no es inferior a la de la tentativa: pena, como en esta -con alguna muy contada excepción-, inferior en uno o dos grados) o entre el dolo eventual y la imprudencia consciente. 
apreciar agresión sexual, sino porque esos conceptos se han llenado de contenido sobre la base de una interpretación acerca de cuál es el comportamiento que debe tener una víctima creíble de violación que solo cabe calificar como sexista. Sexista, porque no tiene en cuenta que hombres y mujeres reaccionan de forma distinta ante una situación de peligro. Sexista, porque no tiene en cuenta qué significado tiene la violación en el control social de las mujeres. Sexista, porque no tiene en cuenta que sumisión o sometimiento no es, en ningún caso, consentimiento. Hay que tener en cuenta, además, que la diferencia entre abuso y agresión sexual se ha utilizado para distinguir entre víctimas que no merecen tanta protección, porque ellas mismas se han puesto en peligro al subir voluntariamente a un piso con varios hombres (caso Arandina) o al emborracharse con ellos (caso de la manada de Manresa), y víctimas que sí la merecen, porque han resistido heroicamente, con riesgo e incluso pérdida de su vida (caso Nagore Laffage). "Solo nos creen cuando nos matan", otro eslogan coreado durante las manifestaciones, tiene lamentablemente todavía mucho de verdad. A ello se añade que la apreciación de la agresión sexual en casos de víctimas menores de edad es anecdótica, y no porque no haya casos de atentados a su indemnidad sexual realizados con violencia o intimidación, sino porque los tribunales entienden que esa violencia o esa intimidación son tan nimias, desde su perspectiva de personas adultas, blancas, universitarias y de clase media, que no merecen ser calificadas como agresión sexual, pese a que haya sido justamente la violencia o la intimidación necesarias para vencer la oposición de una niña de seis, ocho o doce años a las solicitudes sexuales de su padre o de un profesor ${ }^{10}$.

10 Representa una extraordinaria, y ya muy lejana, excepción, la Sentencia del Tribunal Supremo núm. 1366/1999, de 1 de octubre, que ofrece un notable y desacostumbrado ejemplo de atención a las circunstancias del caso. Tras afirmar que, "según consolidada doctrina de esta Sala, por intimidación debe entenderse el anuncio o conminación de un mal, grave, personal y posible que despierte en el intimidado un sentimiento de miedo, angustia o desasosiego ante la posibilidad de un mal real o imaginario que le haga doblegar su voluntad ante lo que se le impone", y que "los hechos mismos 
El "dolor del límite (o de la frontera)" del que habla Gimbernat se puede reducir mucho, aunque no eliminar completamente. Unificar todos los casos de ausencia de consentimiento no elimina todos los problemas, pues siempre habrá que analizar si hubo consentimiento o no. Pero precisamente aquí el anteproyecto introduce otro cambio fundamental. Al señalar que "se entenderá que no existe consentimiento cuando la víctima no haya manifestado libremente por actos exteriores, concluyentes e inequivocos conforme a las circunstancias concurrentes, su voluntad expresa de participar en el acto", el anteproyecto asume que "solo sí es sí", que solo cuando una persona manifiesta de algún modo reconocible por actos exteriores su anuencia, el hecho es lícito. Y todo lo demás es ilícito: penetrar oralmente a

tienen que contener un mínimo coeficiente de idoneidad y significación para suscitar el temor en el ánimo del conminado", declara que "resulta más relevante el aspecto subjetivo de la misma en la medida que tiene que ser suficiente atendiendo primordialmente a las concretas circunstancias de cada caso y muy singularmente a las condiciones y situación en que se encuentre la persona intimidada". "En definitiva", si bien, ciertamente, "la intimidación tiene como presupuesto un mínimo de entidad objetiva", "lo relevante en última instancia es la forma en que la misma ha sido vivenciada por la víctima, por lo que las condiciones de ésta y del entorno en que se producen, vienen a ser determinantes". El ejemplo, decía, es notable y desacostumbrado. Pocas veces han tenido nuestros tribunales una perspectiva de edad $y$ circunstancias como la mostrada en dicho caso. Los hechos probados eran los siguientes: "El procesado Sebastián G. N., mayor de edad y sin antecedentes penales, vino manteniendo de forma continuada desde el año 1988, relaciones sexuales con su hija Diana G. G., nacida el 31-3-1980, cuyas relaciones se desarrollaban en el domicilio familiar sito en esta localidad. Dichas relaciones comenzaron siendo tocamientos que el acusado efectuaba a la menor por todo su cuerpo incluidos sus genitales, para continuar en varias ocasiones no concretadas exigiendo a Diana que le masturbara, a lo que ésta accedía. Por último, en un número de ocasiones no determinado, el acusado penetró vaginal y analmente a la menor, comenzando dichos accesos carnales en una fecha no concretada, pero en todo caso antes de que Diana cumpliese los doce años de edad. A todos estos actos, accedía la menor ante el temor que le inspiraban las amenazas del acusado que aseguraba a la niña en ocasiones que de no acceder a sus deseos, se suicidaría". E1 Tribunal Supremo confirmó la sentencia de instancia y consideró que los hechos eran constitutivos de un delito de agresión sexual, desestimando el recurso de casación, cuyo motivo apoyó el Ministerio Fiscal. 
una joven borracha y semiinconsciente, penetrarla vaginalmente con un dedo cuando está dormitando al sol en una playa nudista, es violación. ¿Lo es también cuando el marido penetra vaginalmente a su esposa adoptando la mujer una actitud meramente pasiva de "dejar hacer"? Gimbernat usa este ejemplo para criticar el anteproyecto, señalando que, cuando sea aprobado, teniendo en cuenta que la violación es un delito público perseguible aun en contra de la voluntad de la persona supuestamente agraviada, el esposo se verá amenazado por una pena de prisión de siete a doce años. Ridículo, frivolizador, ¿no es cierto?

Según Gimbernat, los hechos podrían llegar a juicio aun en contra de la voluntad de la persona supuestamente agredida, pues "basta la querella del Ministerio Fiscal para proceder contra el presunto autor" ". Asumida, a efectos dialécticos, la ceguera del Ministerio Fiscal, que no se sabría bien qué legítimos intereses habría ponderado, es obligado no ignorar un asunto esencial: ¿cómo ha llegado la noticia de tales hechos al Ministerio Fiscal. que desatiende la voluntad de la víctima de no perseguir estos hechos?

El ejemplo citado por Gimbernat es, literalmente, el siguiente: "El marido, muchos domingos, cuando su esposa se ha despertado en el lecho conyugal, la penetra vaginalmente, adoptando la mujer una actitud meramente pasiva de «dejar hacer»". Estereotipos al margen ${ }^{12}$, ¿consiente esta mujer, según lo dispuesto por el anteproyecto? Este declara, recordemos, que "no existe consentimiento cuando la víctima no haya manifestado libremente por actos exteriores, concluyentes e inequívocos, conforme a las circunstancias concurrentes, su voluntad expre-

11 Art. 191.1 CP: "Para proceder por los delitos de agresiones, acoso o abusos sexuales, será precisa denuncia de la persona agraviada, de su representante legal o querella del Ministerio Fiscal, que actuará ponderando los legítimos intereses en presencia. Cuando la víctima sea menor de edad, persona con discapacidad necesitada de especial protección o una persona desvalida, bastará la denuncia del Ministerio Fiscal".

12 Consistentes en atribuir un desmedido apetito sexual a los hombres y en suponer que las mujeres carecen de él. 
sa de participar en el acto". No es preciso un sí con palabras; son suficientes cualesquiera actos exteriores que revelen, de forma concluyente e inequívoca, la voluntad expresa de la persona de participar en el acto. El consentimiento, como exigen otros preceptos del Código Penal (arts. 155 o 156) debe ser válido, libre, espontáneo, consciente, expreso; o, más sucintamente, como prevé el art. 183 quater, libre $^{13}$.

Contrapuesto tradicionalmente el consentimiento expreso al tácito, quizá se ha exigido a aquel más de lo que requiere. "Expreso" significa, según el Diccionario de la RAE, "claro, patente, especificado". Reclamar que la voluntad sea expresa es reclamar que sea clara, que no haya dudas sobre si una persona consiente o no consiente mantener relaciones sexuales. En realidad, esto no debería ser así por imposición legal: nadie debería mantener dichas relaciones con otra persona ( $\mathrm{u}$ otras personas) si alberga dudas sobre si esta (o estas) las consiente (n). Ojo: dudas no sobre si las desea, sino sobre si las consiente. "Consentir" es, una vez más según el citado Diccionario de la RAE, "permitir algo o condescender en que se haga", "soportar o tolerar algo". "Condescender" significa "acomodarse por bondad o conveniencia al gusto y voluntad de alguien", y "tolerar" "Ilevar con paciencia".

¿Consiente la mujer del ejemplo de Gimbernat? Sí, aunque no sienta en ese momento deseo sexual, sus actos revelan, de forma clara, indubitada, su voluntad de participar en la actividad sexual: la permite o tolera, llevándola con paciencia. En otro caso, si sus actos exteriores indican lo contrario, o no patentizan el consentimiento, el contacto sexual será no consentido.

Nos preguntábamos antes si los cambios introducidos por el anteproyecto de ley de garantía de la libertad sexual son necesarios. Y respondíamos que sí, que lo son. Pero no porque

13 Art. 183 quater CP: "El consentimiento libre del menor de dieciséis años excluirá la responsabilidad penal por los delitos previstos en este Capítulo, cuando el autor sea una persona próxima al menor por edad y grado de desarrollo o madurez". 
sean débiles las críticas de Gimbernat u otros, sino porque tienen evidentes virtudes.

La fórmula de lo que se entiende por consentimiento incorpora, en el fondo, una obviedad: solo habrá ejercicio libre de una actividad sexual si esta es consentida por todas las partes; no necesariamente deseada, pero sí, al menos, aceptada como manifestación de una decisión libre.

Pero es preciso subrayarlo, pues en la práctica existe un muy extendido desprecio por la voluntad de las mujeres. SOLO SÍ ES SÍ, por supuesto; pero no es preciso un sí verbal, ni un documento escrito ni, mucho menos, una escritura notarial (al margen de su revocabilidad en cualquier momento). No es posible seguir ignorando si, en realidad, una persona consiente o no participar en una actividad sexual. En caso de duda, debe entenderse que no hay consentimiento.

La exigencia de que concurra un consentimiento claro, patente, especificado, cumple, por otra parte, una doble función preventivo general. El fin del Derecho Penal, existe consenso al respecto, no es, simplemente, castigar, sancionar hechos que se consideran gravemente injustos, sino, sobre todo, prevenir que tales hechos se cometan, pues suponen la lesión o puesta en peligro un bien jurídico relevante.

El anuncio debe ser alto y claro: solo sí es sí. Y debe operar, desde que tenga lugar, el referido doble efecto preventivo general:

- en primer lugar, de carácter negativo o intimidatorio: dirigiéndose a todos los ciudadanos, comunicándoles que, si mantienen relaciones sexuales sin mediar consentimiento o voluntad clara, cometen un delito y deberán ser castigados.

- En segundo lugar, de carácter positivo: se proclama que un determinado bien, la libertad de determinación sexual, tiene un alto valor y, por ello, se ha hecho merecedor de tutela penal. Los destinatarios del anuncio legal ahora son, una vez más, todos los ciudadanos, los potenciales delincuentes, a quienes se 
informa de aquel reconocimiento; pero también ellas, las personas y, muy especialmente, las mujeres, que sean, pese a todo, objeto de atentados sexuales. Deben saber identificar cuándo son partícipes libres en un comportamiento sexual y cuándo son víctimas; poner nombre a lo que desean hacer, pero también a aquello que padecen.

No se trata, por tanto, solo, ni principalmente, de no dejar margen a la impunidad de determinados actos, sino de despertar, de forma sincera, la conciencia social de que el ejercicio de la sexualidad debe ser libre. No es tolerable ignorar o despreciar la voluntad de las personas, actuar con indiferencia hacia dicha voluntad, quizá ignorándola deliberadamente. De otro modo, una persona deja de ser tratada como tal, con dignidad y respeto por su libertad, y se convierte en víctima de nuestros actos. El anuncio legal debe ser manifiesto: no se pretende solo convencer intimidando, asustando, sino, asimismo, y muy especialmente, concienciando, dando a conocer lo que está mal y lo que está bien, fomentando el respeto, la igualdad, la dignidad, la libertad.

Sexo sí, pero sexo libre. En caso de duda, no hay consentimiento. En caso de duda, no debes actuar. ¿Cómo debo interpretar el silencio? Debe haber signos inequívocos que expresen con claridad la voluntad de la persona, que esta desea, o consiente, participar. No hay silencio si, pese a no haber palabras, las acciones, expresiones o gestos no evidencian voluntad de participar. Hay verdadero silencio cuando faltan todas ellas, y entonces, el silencio es negativo. La nueva regulación del consentimiento en materia sexual cumple, en suma, una función de pedagogía social.

Otra virtud de la reforma es situar en el centro del debate lo que verdaderamente importa: no si hubo violencia o intimidación, que es lo que parece sugerir el Código Penal, sino si hubo voluntad libre. El consentimiento sexual debe ser el centro de atención, el elemento nuclear, de los tipos penales.

En el juicio, la atención no debe requerirla, ni solo ni, primeramente, la actitud de la víctima: de ella solo interesa de- 
terminar si consintió o no; no, por el contrario, cómo era su vida sexual antes o como vestía el día de los hechos, o cómo es ahora y cómo viste hoy; si, pese al tan duro golpe que denuncia, no está triste y deprimida, sino bien, feliz incluso tras haberlo superado. No se trata de preguntarse si la esposa, un domingo por la mañana, tiene ganas o no de un revolcón con su marido; si una mujer cualquiera, apenas minutos después de conocer a cinco hombres, consiente en ser penetrada hasta en once ocasiones sin usar condón; o si una niña de quince años consiente en practicar sexo oral con tres hombres, a dos de los cuales acaba de conocer en persona. Se trata de preguntarse si es razonable que el marido crea que su mujer, aunque con pocas ganas o ninguna, acepta sus atenciones, que cinco hombres crean que una mujer consiente en practicar sexo sin protección una vez la han acorralado en un portal o que tres crean que el summum de la felicidad de una jovencita es practicarles sexo oral, incluso tras verla vomitar por el asco y obligarla a limpiar. Conviene aquí hacer una pregunta capciosa. Si en vez de ser una mujer la víctima de la Manada de Pamplona, de los jugadores del Arandina, de la Manada de Manresa, hubiera sido un hombre, ¿qué calificación habrían merecido los hechos? ¿Cambiaría esa calificación si fuera un hombre homosexual?

El anteproyecto no equipara, como denuncia Gimbernat, "el ataque más brutal imaginable contra la libertad sexual (la violación) con otros también muy graves (los abusos sexuales), pero que no alcanzan a aquélla (sic) en su intensidad, porque no se producen empleando fuerza física o psíquica de amenaza con un mal grave"; su redacción no "es equivocada e injusta porque trata penológicamente igual supuestos de hecho desiguales"; antes bien, lo que hace es centrarse en lo que importa, que es la protección de la libertad sexual, entendida como el derecho a no verse involucrado en conductas de contenido sexual a las que no se ha accedido. Lo que importa es, pues, "la penetración vaginal, anal u oral no consentida, con carácter sexual, del cuerpo de otra persona con cualquier parte del cuerpo o con un objeto", y "los demás actos de carácter sexual no consentidos sobre 
otra persona" (art. 36 del Convenio de Estambul). El marco penal es lo suficientemente amplio como para consentir determinar la pena teniendo en cuenta tanto la intensidad del atentado a su libertad de obrar, como si se causaron lesiones físicas o psíquicas, y lo que supere lo que es "normal" en un delito contra la libertad sexual puede tenerse en cuenta por la vía de las circunstancias agravantes de los propios delitos contra la libertad sexual o por la vía del concurso de delitos. Siguiendo estas dos vías, el anteproyecto contempla como circunstancia agravante que "la agresión sexual vaya precedida o acompañada de una violencia de extrema gravedad, de actos que revistan un carácter particularmente degradante o vejatorio, o cause un grave daño a la víctima". Y, además, también prevé que, "si en los delitos descritos en los artículos precedentes, además del atentado a la libertad sexual, se produjere lesión o daño a la vida, integridad fisica, salud, integridad moral o bienes de la víctima o de un tercero, se castigarán los hechos separadamente con la pena que les corresponda por los delitos cometidos, salvo que ya estuvieran castigados con una pena más grave en otro precepto de este Código", precepto con el que, además, se pretende corregir la profunda injusticia que subyace al acuerdo del pleno no jurisdiccional de la Sala Segunda del Tribunal Supremo de 10 de octubre de 2003, cuando entendió que "las alteraciones síquicas ocasionadas a la víctima de una agresión sexual ya han sido tenidas en cuenta por el legislador al tipificar la conducta y asignarle una pena, por lo que ordinariamente quedan consumidas por el tipo delictivo correspondiente por aplicación del principio de consunción del art. 8.3 del Código Penal, sin perjuicio de su valoración a efectos de la responsabilidad civil".

Tampoco compartimos la crítica de Gimbernat a la redacción del art. 178.1 del anteproyecto, realizada, dice, "desconociendo la más elemental regla de técnica legislativa de que en los tipos penales, para llegar a un concepto legal, primero hay que buscar lo que es común en la multitud de casos a los que se quiere abarcar como constitutivos del delito en cuestión, para después, mediante un proceso de abstracción, establecer 
una definición genérica en la que sea posible subsumir todos aquellos casos en su múltiple variedad"14. No solo no está ausente dicha elemental regla de técnica legislativa, sino que está especialmente presente. La fórmula legal proyectada es aún más amplia que las actuales y toma como base lo que es común a toda la multitud de casos que se pretende abarcar: la ausencia de consentimiento. Este es el verdadero contenido de injusto de todo atentado de naturaleza sexual, la lesión de la libertad sexual.

Dice también Gimbernat que, "para acabar de arreglarlo, el Anteproyecto ni siquiera ha interpretado correctamente los elementos fácticos relevantes -centrándolo todo en el consentimiento expreso- del caso La Manada. En este caso habría

14 "De esta manera, y por ejemplo, la magnifica definición abstracta de la estafa del art. 248.1 del vigente CP ("Cometen estafa los que, como ánimo de lucro, utilizaren engaño bastante para producir error en otro, induciéndolo a realizar un acto de disposición en perjuicio propio o ajeno") abarca, por una parte, todos los supuestos imaginables de este delito que pueden presentarse en la realidad-desde el timo del tocomocho hasta la más refinada y multimillonaria estafa piramidal-, al tiempo que deja fuera del Derecho penal otros perjuicios patrimoniales que puedan irrogársele a otra persona, pero que no sobrepasan la esfera del mero ilícito civil". La definición abstracta de la estafa del art. 248.1 CP nos parece, en efecto, magnífica, si bien evidenció con el paso del tiempo muchas carencias que exigieron considerar también estafas otros comportamientos previstos hoy en el art. 248.2 CP (al margen, por otra parte, de los tipificados en el art. $251 \mathrm{CP}$ ).

"Frente a este proceso de, primero, analizar la multitud de casos que, como constitutivos de delito, se quieren abarcar en un tipo penal, para, después, $y$ teniendo en cuenta todos los elementos comunes que comparten, llegar, finalmente, a la definición abstracta del correspondiente delito, el prelegislador del Anteproyecto lo ha puesto todo del revés: ha arrancado de un caso concreto: del de La Manada, y para que no se repitan sentencias como las de los tribunales navarros, que no condenaron por violación, exige, en todo caso, para que no concurra una agresión sexual, que la víctima consienta "expresamente" en el acto sexual; con ello, y al obviar todos los demás y numerosos supuestos de violación y de abusos por prevalimiento que pueden presentarse en la vida real, ha establecido una definición legal de agresión sexual que prescinde de cualquier clase de abstracción, hasta el punto de considerar violación, disparatadamente, también la relación sexual en la que la mujer, libremente, consiente tácitamente en esa relación". 
existido también violación, aunque la víctima -sometida a la brutal coacción de la que estaba siendo objeto- hubiera manifestado su consentimiento expreso de tolerar los accesos carnales a los que la sometian, porque ese consentimiento no habria sido libre -y, por consiguiente tampoco eficaz-, sino un producto más de la misma intimidación con la que le obligaron a soportar las agresiones sexuales. Ante la intimidación a la que la sometían los cinco integrantes del grupo, con o sin consentimiento expreso, en el caso La Manada estaríamos siempre ante una violación, porque, como manifiesta el TS en su sentencia de 4-72019, "[i]ntimidar no es otra cosa que causar o infundir miedo, miedo o pánico que, en casos como el analizado [La Manada], se infunde con la sola presencia de cinco individuos de fuerte complexión rodeando a una víctima en un habitáculo cerrado y sin posibilidad alguna de escapar", ya que la intimidación en la violación consiste en "el uso de un clima de temor o de terror que anula su capacidad [de la víctima] de resistencia".

Absolutamente de acuerdo: aunque la víctima hubiera dicho sí, este habría sido inválido, nulo de pleno derecho, y la conducta igualmente delictiva y, en concreto, constitutiva de un delito de agresión sexual por concurrir intimidación. Pero ello no es ignorado por el anteproyecto, cuyo objetivo, como se ha explicado, es mucho más ambicioso.

Compartimos, ahora sí, la crítica de Gimbernat, Pablo Iglesias mediante, de que ningún texto prelegislativo o legislativo puede estar sustraído a la crítica. La crítica, en efecto, enriquece. Si es constructiva y respetuosa, y la de Gimbernat es ambas cosas, obliga a buscar argumentos, permite atender nuevos puntos de vista y detectar puntos débiles y replantear lo proyectado o lo que ya alcanzó rango legal. De acuerdo, por consiguiente, en que "contra esta pretendida «tabuización» del Anteproyecto hay que decir que ni éste, ni ningún otro texto prelegislativo o legislativo están sustraídos a la crítica. Y que esa crítica -tal como la que se ha expuesto en este artículo-, en un mundo donde impere la racionalidad, no puede ser combatida 
con exabruptos, sino sólo con argumentos que eventualmente puedan convencer de que uno está equivocado".

A nosotros, sin embargo, sí nos convencen los dos grandes cambios, aquí analizados, que introduce la reforma. Calificando todo atentado a la libertad sexual como agresión ${ }^{15}$ se pone especialmente de manifiesto que la conducta atenta contra la libertad sexual en la medida en que no fue consentida; calificando como violación todo atentado sexual, toda agresión, consistente en acceso carnal por vía vaginal, anal o bucal, o en introducción de miembros corporales u objetos por alguna de las dos primeras vías, el anteproyecto, en fin, permite llamar a las cosas por su nombre, pues las palabras, en efecto, importan.

15 Término utilizado, por cierto, para referirse, de forma general, en ocasiones, a todo atentado a un bien jurídico y, de modo particular, a las agresiones, incluso leves, que sufre cualquier persona o, en el delito de atentado, las autoridades o funcionarios públicos. 